\title{
Universiteit
}

Leiden

The Netherlands

\section{The limits of ethnic capital: impacts of social desirability on Korean views of} co-ethnic immigration

Denney, S.; Ward, P.; Green, C.K.

\section{Citation}

Denney, S., Ward, P., \& Green, C. K. (2022). The limits of ethnic capital: impacts of social desirability on Korean views of co-ethnic immigration. Journal Of Ethnic And Migration Studies, 48(7), 1669-1689. doi:10.1080/1369183x.2020.1797477

Version:

Publisher's Version

License:

Licensed under Article 25fa Copyright Act/Law (Amendment Taverne)

Downloaded from: https://hdl.handle.net/1887/3200880

Note: To cite this publication please use the final published version (if applicable). 


\section{The limits of ethnic capital: impacts of social desirability on Korean views of co-ethnic immigration}

\section{Steven Denney, Peter Ward \& Christopher Green}

To cite this article: Steven Denney, Peter Ward \& Christopher Green (2020): The limits of ethnic capital: impacts of social desirability on Korean views of co-ethnic immigration, Journal of Ethnic and Migration Studies, DOI: 10.1080/1369183X.2020.1797477

To link to this article: https://doi.org/10.1080/1369183X.2020.1797477

View supplementary material $₫$

\section{曲 Published online: 27 Jul 2020.}

Submit your article to this journal $\llbracket$

山ll Article views: 337

Q View related articles $\longleftarrow$

View Crossmark data $\nearrow$ 


\title{
The limits of ethnic capital: impacts of social desirability on Korean views of co-ethnic immigration
}

\author{
Steven Denney ${ }^{\mathrm{D}}{ }^{\mathrm{a}}$, Peter Ward ${ }^{\mathrm{b}}$ and Christopher Green ${ }^{\mathrm{c}}$ \\ ${ }^{a}$ Munk School of Global Affairs and Public Policy, University of Toronto, Toronto, Canada; ${ }^{b}$ Department of East \\ Asian Economy and Society, University of Vienna, Wien, Austria; 'Institute for Area Studies, Leiden University, \\ Leiden, Netherlands
}

\begin{abstract}
A substantial body of research has found that social desirability motivates respondents to overstate support for immigration when asked directly, but when provided an unobtrusive means of expressing preferences, support declines. In this paper, we ask whether South Koreans follow this pattern, especially with regards to co-ethnic migrants from North Korea and China. We use list experiments to determine whether observed levels of support for general immigration and co-ethnic migration are biased by social desirability. We find that generally respondents overstate their support for co-ethnics from North Korea by a significant amount when asked directly, but not for the other groups, although college-educated respondents overstate their support for general immigration. Social desirability bias with respect to co-ethnics from North Korea is particularly evident in older respondents and males. These findings challenge the notion that native-born citizens prefer co-ethnic immigrants.
\end{abstract}

ARTICLE HISTORY

Received 4 November 2019

Accepted 21 June 2020

\section{KEYWORDS}

Immigration; ethnicity;

national identity; list

experiment; Korea

\section{Introduction}

It is an oft-stated claim that the people of North and South Korea belong to a single ethnic nation, and that the division of the Korean peninsula since 1945 represents a historical aberration. The concept of the two Koreas as one, and of national unification as both a historical inevitability and the supreme Korean virtue, is repeated by governments, in classrooms, and on the street. It is the basis of Seoul's unification discourse and the constitutional claim that the Republic of Korea (South Korea) is the sole legitimate ruler of the peninsula (a mantle that Pyongyang also claims for North Korea, known officially as the Democratic People's Republic of Korea). When polled, a majority of South Koreans articulate an affinity for the pan-Korean nation, assert the need for North-South unification, and give reasonably positive views of those who leave North Korea and resettle in the South (Jeong et al. 2018).

There is, however, a body of literature that points to the status of incoming North Koreans as outsiders, and as subject to differentiated treatment from not only the South Korean state (Choe 2018), but also from South Korean society at large (Hough 2017). 
Testimony from North Korean defector-migrants ${ }^{1}$ about their lives in South Korea shows that, seemingly contrary to polling data, they are treated differently to native-born South Koreans, and frequently rather poorly (Kim and Yoon 2015). When asked, some - seemingly many - newcomers say they feel they are merely regarded as, and treated like, just another immigrant group. One defector-migrant interviewed by us in 2016 explained, 'South Koreans claim we are one, based on our common ancestry, but in reality, they see us as a part of a multicultural Korea. We are like immigrants'. All of which serves to highlight an apparent gap between South Koreans' stated preferences vis-à-vis North Korean coethnic arrivals and the daily treatment afforded to those same co-ethnics. ${ }^{2}$

What might explain the observable divergence between South Koreans' stated preferences and actual behaviour? One possible conclusion, especially regarding North Korean defector-migrants, is that survey respondents simply fail to live up to their stated preferences in practice. Another is that these polling data are not an accurate reflection of South Koreans' true preferences. Do respondents feel able to say what they actually think when asked directly, as they invariably are, or are their responses altered by social desirability bias, meaning that polling data does not reflect actual preferences?

And what about South Koreans' opinion towards immigration to their country in general? To what extent might support for all immigration be biased by a similar desire to provide a socially acceptable answer? Cross-national polls on national identity and immigration present a positive picture, suggesting that South Koreans respondents are as accepting of newcomers, and in some cases more so, than those from more diverse and equally democratic societies (Boyon 2018, 14-23; Poushter, Feteerfolf, and Tamir 2019). But research indicates that such data can be biased as well (cf. Janus 2010; Creighton, Jamal, and Malancu 2015).

In this paper, we employ list experiments to determine whether observed levels of support for different types of immigration into South Korea are biased by social desirability. Specifically, we ask if direct questions about support for immigration reflect true preferences, or if social desirability leads South Korean respondents to preference falsification, and if so, with what implications. We examine levels of support for immigration overall, as well as that of North Korean defector-migrants and also of a second, much larger group of co-ethnic migrants to South Korea, the ethnically Korean Joseonjok (or Chinese Koreans). Looking across social groups, we also consider whether there are any heterogeneous treatment effects.

Overall, we find evidence of social desirability bias in answers to direct questions about defector-migrants. Respondents profess relatively high levels of support for co-ethnics from North Korea when asked directly, but when asked indirectly via the list, support declines considerably. Conversely, direct and indirect estimates are not significantly different for general immigration or co-ethnics from China. The findings suggest specific social expectations about how one is expected to think about defector-migrants, but not about Chinese Koreans, raising doubts about the applicability of ethnic capital as a way to explain respondent preferences. When treatment effects are considered across social groups, we also find evidence that college-educated respondents overstate their support for immigration overall, in addition to that for defector-migrants. ${ }^{3}$ Social desirability bias in the direct estimates about co-ethnics from North Korea is also particularly evident in older respondents and males. The findings presented in this paper challenge the notion of a general co-ethnic preference for new immigrants. The results also 
show that, in South Korea, citizens are conditioned to support North Korean migration, when in fact their support for this group is no higher than it is for general immigrants.

\section{Immigration and South Korea}

Immigration has emerged as a polarizing issue in many economically developed countries. Clashes at the United States-Mexico border and southern entry points of the EU are among the most visually affecting examples of a trend that has thrust the topic up the political agenda. In several advanced economies, political entrepreneurs have successfully channel popular ambivalence or hostility toward newcomers (Norris and Inglehart 2019).

It is therefore interesting that South Koreans appear relatively sanguine about their rising immigrant population, even as it has brought with it noteworthy social, economic, and demographic changes. In 1995, the foreign resident population of South Korea, a category that counts both temporary and permanent residents, was just 0.24 percent of the national population ( $\operatorname{Lim}$ 2017). A little over two decades later in 2018 it was 2.36 million, 4.6 percent of the national population, a 20 -fold increase and rising. ${ }^{4}$ According to recent data on the composition of the permanent resident migrant population in South Korea, almost one-third of all immigrants $(497,656)$ are Chinese Koreans (the aforementioned Joseonjok) and 14 percent are Chinese (not ethnically Korean; a further 212,072). By comparison, the North Korean defector-migrant population of South Korea is small, numbering just 31,339 in $2017 .^{5}$

Influential think tanks, frequently utilizing government funding, have produced reports purporting to demonstrate that immigration is essential to securing the future of the national economy - threatened as it is by a rapidly ageing population. One study by the Korea Economic Research Institute (KERI) warned that the number of immigrants living in the country would have to rise to almost 5 million by 2020 and more than 17 million by 2060 to ensure that population growth rose to and then remained above replacement rate (Cho and Kang 2015, 84-88). ${ }^{6}$ Another report published by the IOM Migration Research and Training Centre reached a comparable conclusion, estimating that 4.8 million foreign workers by 2040 would be needed to maintain current rates of GDP growth (around three percent per annum since $2017^{7}$ ) that the country currently enjoys (Kang et al. 2015, 162). ${ }^{8}$

Although a restrictive visa regime means that South Korea will fall well short of the 2020 target of 5 million immigrants that the KERI study's findings suggest is necessary, the government in Seoul has been quick to support those immigrants who do enter the country and advocates the notion of South Korea as an increasingly multicultural society. As $\operatorname{Kim}(2015,730)$ notes, state institutions and key political figures are swift to emphasize the value of newcomers. At the national and local levels, efforts are made to integrate immigrants, especially those who marry South Korean citizens, into the national community through education and other support activities (Kim 2016).

There is little open contestation in South Korean society over the appropriateness of this approach. Public opinion would appear to be broadly supportive with over twothirds of respondents to the South Korean state-funded 2018 'Citizens Multiculturalism Acceptance Survey' indicating that they were unconcerned by, or perhaps indifferent, to immigration and that current immigrant numbers seemed appropriate. Over 76 percent of respondents said that immigrants neither made the country better or worse to live 
in, and more than 64 percent did not mind whether immigrants became their neighbours (Kim et al. 2018, 297-299). Cross-national surveys find South Koreans' views on immigration, diversity, and nationality to align closely with those of diverse, democratic societies (Boyon 2018; Poushter, Feteerfolf, and Tamir 2019).

However, there is also evidence that all groups of newcomers are not regarded as equal, not only by the South Korean immigration system but also by society at large. Survey data suggests South Koreans prefer co-ethnics over non-Korean migrants (Yoon 2016). ${ }^{9}$ Accordingly, social norms surrounding co-ethnics and the country's visa system uphold and reproduce a hierarchical notion of citizenship. Here there is a skills component, with less-skilled ethnic Koreans - principally from China - accorded lower status and granted fewer rights and benefits than Korean Americans, who are seen as the most desirable co-ethnic group (Lee and Chien 2017; Lim and Seol 2018; Seol and Skrentny 2009). Seol and Skrentny (2009), Choi (2016) and Oh and Oh (2016) demonstrate how this ethnic hierarchy determined largely by country of origin is reflected in both policy and popular opinion and reflected in cultural productions.

Given the conditional nature of South Korean multiculturalism, specifically the importance ascribed to transferable skills and relative status, it is at least somewhat surprising that South Koreans show high levels of support for the resettlement of North Korean defector-migrants. This is a group whose members speak fluent Korean, ${ }^{10}$ but are otherwise unskilled newcomers from a low-status country who are known to face significant difficulties in making economic adjustments post-resettlement (Yu et al. 2012; Kim, Lee, and Kim 2013; Kim and Lee 2018). ${ }^{11}$ In spite of the costs associated with resettlement, which almost exclusively fall upon the taxpayers, surveys find that South Korean respondents report high levels of closeness to North Korean refugees relative to most other immigrant groups (Jeong et al. 2018, 312-318). Most South Koreans also profess to have a positive view of North Korean refugees as potential friends and neighbours (Lee et al. 2018), and support their migration over that of other co-ethnic groups, like Chinese Koreans (Ha, Cho, and Kang 2016). ${ }^{12}$

It is largely assumed that respondents do not conceal their true preferences when surveyed about immigration in general and co-ethnic immigration in particular. This is, however, a questionable premise. The expectation that co-ethnics, especially defectormigrants, ought to be supported is a clearly ingrained feature of South Korean society. There is every reason to believe that respondents may provide socially conditioned responses rather than their real opinions due to the sensitivity of the topic. It is less clear that South Koreans are expected to profess greater support for immigration in general (immigration as a salient phenomenon is a recent development), but here, too, further investigation is warranted. Social expectations and desirability pose a critical challenge to observational data, but also an opportunity to determine where it impacts opinions and why.

\section{Social desirability bias and list experiments}

List experiments (also known as the 'item count technique') have been used widely in the social sciences to make estimates about support for or opposition to sensitive issues, or the actual incidence of risky or socially taboo behaviours. The technique counters the fact that when respondents believe it is socially undesirable to admit to supporting a sensitive or 
controversial attitude or admit to having engaged in a particular behaviour, they are more likely to falsify their true beliefs or behaviours (Krumpal 2013). ${ }^{13}$

The list experiment approach has been used to estimate the effects of both social desirability bias and to estimate the actual prevalence of a wide range of different phenomena. These include politically sensitive matters such as vote buying (Gonzalez-Octanos et al. 2012), reported voter turnout (Holbrook and Krosnick 2010), as well as risky social behaviours like sexual behaviour and alcohol consumption (LaBrie and Earleywine 2000; Walsh and Braithwaite 2008), and politically and socially taboo activities such as antigay hate crime rates amongst college students (Rayburn, Earleywine, and Davison 2003).

The list technique has also been used to ascertain views on race and matters related to views of the national community in the United States. These include attempts to measure opposition to affirmative action (Kuklinski et al. 1997; Gilens, Sniderman, and Kuklinski 1998), opposition to a black person becoming President of the United States (Martinez and Craig 2010), and opposition to a Jewish candidate becoming President/Vice President of the United States (Kane, Craig, and Wald 2004).

Important to the research presented here, research into attitudes toward immigration has also benefited from the use of list experiments. Janus (2010) finds a desire to restrict immigration even amongst more well-educated US respondents. In a US context, where higher levels of education are often believed to be associated with greater tolerance for immigration (Burns and Gimpel 2000), this demonstrates the power of social desirability bias in observational survey data that explore the sensitive topic of immigration, and the potential for list experiments to detect such bias. Conversely, Donnelly (2017) considers support for immigration and the acceptance of Syrian refugees to Canada, finding little difference between direct and indirect methods of estimating support.

Creighton, Jamal, and Malancu (2015) use a list experiment to determine true levels of support for stopping all immigration in order to obtain a more accurate estimate of the relative prevalence of such sentiments. Their results indicate, interestingly, that social desirability bias distorts survey responses less after the Global Financial Crisis of 2008, with respondents being less prone to lie about being opposed to banning all immigration after the crisis. The authors' work indicates that major political and economic events can make some views less socially undesirable. Conversely, An (2015) finds evidence commensurate with Janus (2010), that Americans, especially the better educated, are prone to social desirability effects when answering questions about immigration. When asked directly, 72 percent of university graduates say they oppose immigration restrictions, but this number plummets to 38 percent when estimated using a list experiment design (An 2015, 465).

This paper uses list experiments to ascertain whether observational survey data that appears to reveal South Korean support for co-ethnic immigration is subject to social desirability bias. It looks at levels of support for immigration in general alongside that for two co-ethnic groups: North Korean defector-migrants and Chinese Koreans. These three groups were deliberately chosen. Attitudes to immigration overall reveal the extent to which immigration is a salient topic, such that respondents might be uncomfortable admitting an opinion contra South Korea's status as an open and middle power with a commitment to democratic international norms. North Korean defector-migrants were chosen as representing a normatively desirable co-ethnic group, given peninsula history, cultural and ethnic commonalities, and the fact that the acceptance of this group is widely promoted as a civic virtue. We chose Chinese Koreans as the third group because they are 
co-ethnics, and therefore, if Korean ethnic nationalism were to motivate opinions across cases, would also be considered part of the Korean ethnic nation and thus viewed similarly to North Koreans.

The personal cost of falsifying responses on surveys is negligible, while being honest may cause what many survey respondents see as unnecessary discomfort. In the South Korean case, avoiding such discomfort would mean professing a view in line with liberal international norms on general immigration to South Korea, and giving support for co-ethnics in particular. This could then mask the absence of a strong sense of ethnic solidarity. Absent evidence to the contrary, the assumption is that respondents do not falsify preferences when asked directly. This is, after all, the assumption behind observation survey methods, but it is clear why respondents may choose to conceal their true beliefs. The logical discussion is about why Koreans falsify their preferences, not about why they do not. Thus, our main hypotheses read as follows:

$H_{1}$ : South Koreans falsify their preferences when asked about immigration in general.

$\mathrm{H}_{2}$ : South Koreans falsify their preferences when asked about co-ethnic immigration.

In addition to our empirical expectations outlined above, we have reason to believe that not all social groups will respond similarly when given an unobtrusive way of expressing their opinion. Age, education, and gender may mediate the experimental interventions. The justification for our belief is both general and theoretical, but also specific to the South Korean context.

First, literature on immigration attitudes finds significant differences in opinion by age or generations (Norris and Inglehart 2019, 175-212), with younger people generally showing greater support for immigration in general, a finding confirmed for South Korea by Denney (2019, 71-78). Campbell (2016) and Denney (2019) show that younger South Koreans are less likely to hold an ethno-national conception of nationhood and belonging. That is, there is less of an expectation for younger Koreans to show co-ethnicity solidarity. Yet, it remains unclear whether young people's observed levels of support reflect their true preferences or a social expectation that, as a young(er) person, one ought to support immigration. We thus add the following hypotheses for empirical testing:

$H_{3}$ : Younger South Koreans falsify their preferences when asked about immigration in general.

$\mathrm{H}_{4}$ : Younger South Koreans falsify their preferences when asked about co-ethnic immigration.

Similarly, studies point to the importance of education on attitudes towards immigration (Krysan 1998). Given their experiences in higher education, college-educated citizens are understood as holding more open and progressive views on immigration (Gaasholt and Togeby 1995; Sorensen and Krahn 1996). This view enjoys fairly robust empirical support (Mayda 2006; Hainmueller and Hiscox 2007). However, as explored above, An (2015) and Janus (2010) find that college-educated Americans are more prone to overstate their support for immigration when asked directly, likely due to the university experience and social expectations associated with being an educated citizen.

It stands to reason that a similar social expectation exists in South Korea. What we expect regarding college-educated attitudes towards co-ethnics is less clear, but research shows that education and ethno-national conceptions of national belonging are negatively associated (Chang and Wang 2005; Kunovich 2009), meaning that educated citizens in 
South Korea likely feel less obliged to support co-ethnics, and may even find doing so undesirable. They would therefore be less likely to conceal true preferences if asked directly. To address possible heterogeneous effects by education, we add two additional hypotheses:

$H_{5}$ : College-educated South Koreans falsify their preferences when asked about immigration in general.

$H_{6}$ : College-educated South Koreans falsify their preferences when asked about co-ethnic immigration.

Lastly, we view gender as a crucial mediating variable. The mediating effects of gender on attitudes to immigration have been reviewed in studies of immigration attitudes in Europe and the United States (Fussell 2014; Ponce 2017), finding contradictory evidence about male and female attitudes. There is ample reason for closer investigation in the case of South Korea. As Moon (2005) shows, Korean nationhood and identity are rigidly gendered. Men, in particular, are seen as holding highly patriarchal views (Kim 2006) and, due primarily to mandatory military service, militaristic and/or nationalistic views on nationhood (Kwon 2001). There are, we theorize, much stronger expectations placed on South Korean men to support co-ethnic migrants (ethno-national nationhood) but not immigration overall (a threat to male-dominated social conventions).

$H_{7}$ : Male South Koreans falsify their preferences when asked about immigration in general.

$H_{8}$ : Male South Koreans falsify their preferences when asked about co-ethnic immigration.

\section{Design, questions, and data}

In the list experiments employed here, respondents are randomly assigned to one of the two types of lists and then asked to report the number of items they are opposed to (not which ones). All lists contain mundane, non-sensitive items. Of three possible lists, two contain sensitive immigration items, and the control list consists of only non-sensitive items. The unobtrusive nature of the design gives respondents plausibility deniability in not opposing an item society might otherwise expect them to oppose (e.g. not accepting North Korean defector-migrants). Respondents were introduced to the list as follows:

Below is a list of things that some people oppose or are against. Please count how many of them you oppose and input the number below.

Respondents were then shown one of the three lists. The group shown the list containing only mundane items serves as the control group. These items include the following:

- The Korean government increasing aid to the poor

- Movie stars making millions of dollars per year

- Large corporations polluting the environment

Respondents in the treatment groups were shown one of the following sensitive items:

- Halting all immigration to South Korea 
- Halting North Korean defectors from entering South Korea or

- Halting Chinese Koreans from entering South Korea

Following the recommendation of Kramon and Weghorst (2019) and Blair and Imai (2012), direct questions were shown to all respondents. Prior to the list, all respondents were asked to answer whether they 'agree', 'disagree', or 'don't know' regarding the extreme policy measure. The direct questions, and possible answers, read as follows:

Would you support or oppose stopping all immigration into South Korea?

- Oppose

- Neither support nor oppose

- Support

Would you support or oppose stopping the entry of North Korean defectors into South Korea?

- Oppose

- Neither support nor oppose

- Support

Would you support or oppose stopping the entry of Chinese Koreans into South Korea?

- Oppose

- Neither support nor oppose

- Support

We count those who disagree as one, else zero, yielding a proportion of respondents who support general immigration, North Korean defector-migrants, or Chinese Korean immigrants. Those who are coded as ' 0 ' should not be understood as supporting the extreme policy measure proposed but read as not opposing it. Consistent with existing data, ambivalence is a popular position. ${ }^{14}$

Since the sensitive questions ask about one's opposition to halting immigration or entry of a specific group, higher number estimates can be read as being more pro-immigrant or an expression of solidarity with a co-ethnic group (North Korean defectors and Chinese Koreans). Following similar list experiment designs (Gilens, Sniderman, and Kuklinski 1998; Janus 2010; Creighton, Jamal, and Malancu 2015), the difference in proportions between the direct and indirect responses are used to determine whether social desirability bias is present in responses to direct questioning. A statistically significant and substantive difference between the proportions would constitute evidence that respondents over- or possibly under-estimate their support for immigration when asked directly.

The questions were administered in three immigration attitudes surveys between December 2018 and May 2019 with Rakuten Insights' South Korea panel. ${ }^{15}$ Each survey contained a battery of immigration questions and the list experiments. 1,008 respondents participated in both the first (December 2018) and second (February 2019) surveys, which are referred to as panels A and B, respectively. The lists for panels A and B contain sensitive items for general immigration and defector-migrants. A total of 410 participated in the third survey (May 2019), or Panel C. Only participants from panel C were exposed to the sensitive item for Chinese Koreans (they were not asked about general immigration). An 
overview of the survey questions, descriptive statistics for the direct questions explored here, and balance testing by control and treatment groups is provided in Appendix B of the Supplementary Information.

\section{Estimating opposition to immigration}

\section{Difference-in-means}

Simple analysis of the list experiment is done using a difference-in-means estimator (Imai 2011). In this method, the difference in the average number of items opposed in the control group (items 1-3) is subtracted from the average number of items opposed in the treatment group (one of the three lists with sensitive items). Given the assumptions described above, the difference-in-means estimation yields an unbiased proportion of respondents who disagree with the sensitive items (i.e. support immigration). The difference between the list proportion and the average score from the direct question indicates the presence (or absence) of social desirability bias. Higher estimates from the direct questions would indicate that respondents overstate their support due to social desirability.

Figure 1 shows the list estimates and direct averages for sensitive items across panels. Averages from the direct questions for the sensitive items indicate that respondents have a relatively high level of support for North Korean defector-migrants. Whereas only 30-35 percent of respondents oppose barring immigration altogether or halting the immigration of Chinese Koreans, between 48 and 50 percent of respondents oppose barring entry to North Korean defector-migrants. Co-ethnics from North Korea are clearly the most preferred group among those considered. However, when we compare direct estimates to the list-based averages, the findings change considerably.

The list experiment findings based on the difference-in-means estimation indicate that respondents' true preferences are concealed when asked directly about North Korean

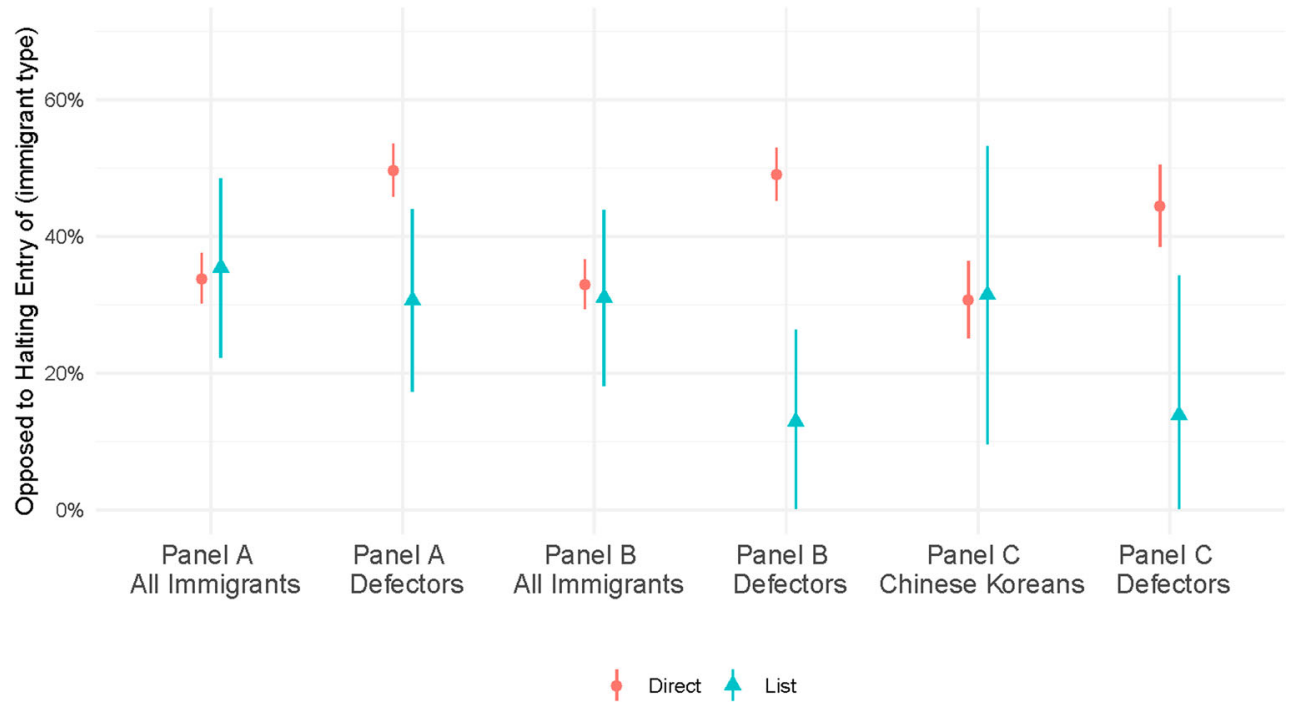

Figure 1. Difference-in-Means: South Korean Attitudes Towards Immigration by Panel, Immigrant, and Question Type. Error bars represent 95\% confidence intervals. 
defector-migrants. The difference in proportions between the list and direct question for the North Korean defector-migrant item are substantial across all three panels. When asked directly, 50 percent of all respondents in Panel A said they opposed halting the entry of North Korean defectors. The level of support for this group declines to 31 percent when respondents are asked the same question in an unobtrusive way - a 29 percentage point (pp) difference. In panels B and C, the differences are even larger at 36pp and $31 \mathrm{pp}$, respectively. Respondents do not, however, show any difference in opinion by method of inquiry regarding general immigration or Chinese Koreans. There is apparently no social pressure to conform to a particular view; true preferences regarding Chinese Koreans are revealed when asked directly.

\section{Multivariate analysis}

Advances in methods (Imai 2011; Blair and Imai 2012) show that using a maximum-likelihood estimator (MLE) yields a completer and more efficient estimate. The MLE is considered superior to the conventional difference-in-means technique as it uses all information from the joint distribution and permits researchers to conduct multivariate analysis. We employ the MLE here, with controls included for age, education, and gender. Using the same model parameters as the MLE, a generalized linear model (GLM) is used for estimating proportions on the direct question. Again, we compare the difference between the two proportions to determine whether respondents are falsifying their true preferences when asked about a sensitive issue directly. Tabular output for the model estimates, including outcomes of means tests of differences, is provided in Appendix B. ${ }^{16}$

Figure 2 shows the estimated proportion of respondents who oppose halting immigration for all immigrants or a co-ethnic group. Comparing the ML and GLM estimates, we

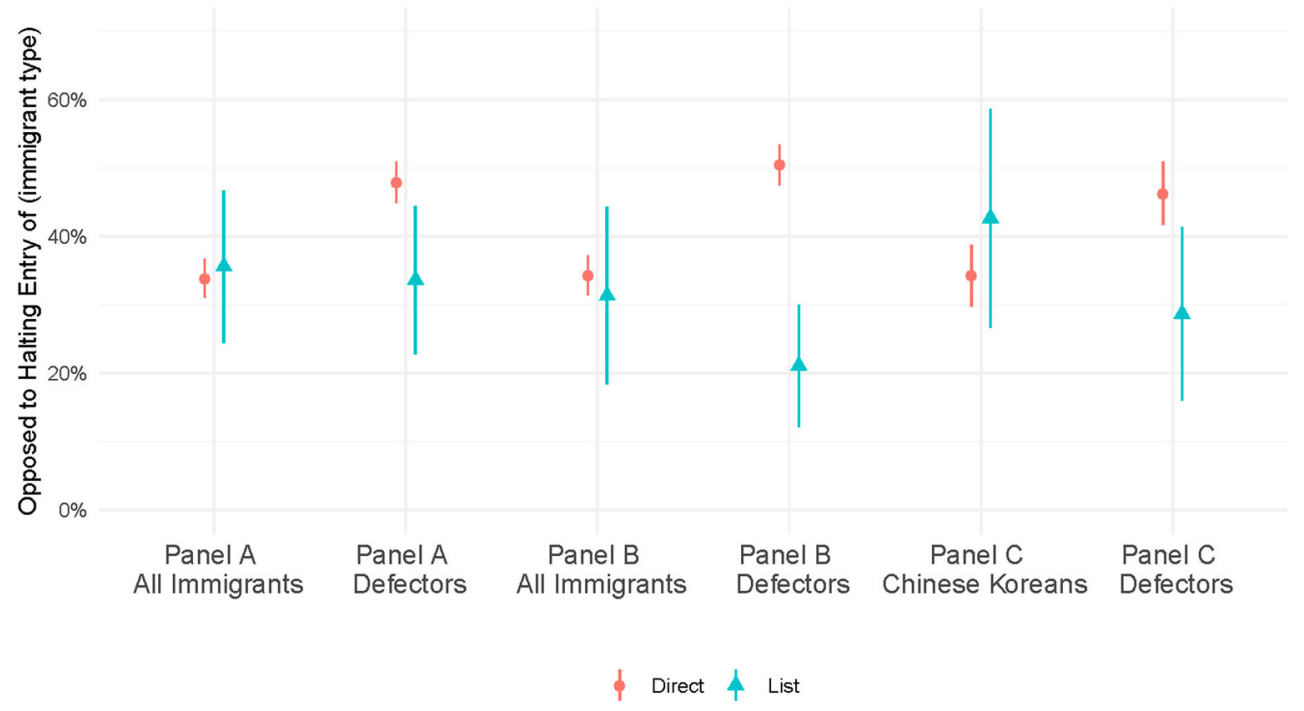

Figure 2. Maximum Likehood Estimator South Korean Attitudes Towards Immigration by Panel, Immigrant, and Question Type. Error bars represent 95\% confidence intervals. 
find again that across all three panels South Korean respondents overestimate their level of solidarity with North Korean defector-migrants. ${ }^{17}$ In this case, the difference is anywhere from 14-29 percent. Panels A and C show 14 and 18 percentage point (pp) differences between direct and list estimations, respectively, while panel B shows a 29pp difference. It is unclear why there are such significant differences between panel A and the others, but the core finding is consistent across the panels: when asked directly respondents overstate their support for co-ethnics from North Korea. The evidence presented here suggests that South Koreans are socially conditioned to express a higher degree of solidarity with North Korean defector-migrants than they would otherwise state given an unobtrusive way of expressing their preference.

Conversely, and as observed with the difference-in-means estimation, respondents do not overstate support for co-ethnics from China; directly expressing one's true preference towards this group is acceptable. In fact, one may be expected to express less solidarity with Chinese Koreans when asked directly. There is an 8pp difference between the list and direct estimates for the Chinese Koreans item, but in the direction opposite that of North Korean defector-migrants. The difference, however interesting, is not statistically significant ( $p$-value <.05).

In panels $A$ and $B$, the differences in proportions for halting all immigration to South Korea are 2-3pp; they are neither statistically nor substantively different. The evidence indicates there is no desire to conceal true preferences about immigration in general. The absence of statistically significant differences in proportions for all immigration provides strong corroborating evidence of social desirability bias in direct estimates about North Korean co-ethnics. We find no evidence that either of the core assumptions of the list experiment explained above are violated. ${ }^{18}$

Lastly, for purposes of statistical precision and simplicity in presenting the main findings, we pool panels A and B. The new dataset contains 2,016 observations. Because of differences in design/questions, Panel $\mathrm{C}$ (which include the Chinese Korean group) is excluded. ${ }^{19}$ Using identical ML and GLM model parameters as above, plus a survey panel fixed effect variable (to correct for panel differences), we re-estimate opposition to barring general immigrants and defector-migrants. Figure 3 shows a 23-percentage point difference in averages between direct and list estimates for North Korean defector-migrants. The difference (1pp) for all immigrants is insignificant, statistically and substantively (see findings in tabular form and significance tests overview in the Appendix). The social desirability bias in direct estimates of support for North Korean defectormigrants is clear. In fact, if the list estimates are taken as the true, unbiased preferences of South Korean respondents, then there is less support for defector-migrants (26 percent) than general immigrants (32 percent).

\section{Heterogeneous treatment effects}

Using the standard difference-in-means and maximum likelihood estimators, we find evidence of social desirability bias in estimates for support of defector-migrants using direct questions. Are there any heterogeneous treatment effects? In this section, we re-estimate the maximum likelihood models on the pooled sample by age cohorts, education, and gender. For age cohorts, we use three levels: ages 18-29, 30-59, and 60 and older. ${ }^{20}$ Next, those with some college education are compared to those without, to empirically 


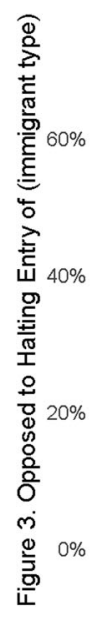

Panels $A+B$

All Immigrants

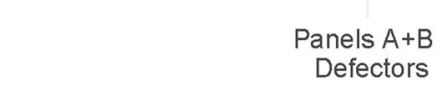

Direct 4 List

Figure 3. Maximum Likehood Estimator South Korean Attitudes Towards Immigration by Panel, Immigrant, and Question Type. Error bars represent 95\% confidence intervals.

resolve whether having a college-education means one is more likely to falsify preferences. Lastly, we look for evidence of gender effects, especially among men. Tabular output, including significance testing, is included in Appendix B.

Figure 4 shows heterogeneous treatment effects by age cohorts. First, for questions regarding all immigrants, we observe some differences between direct and indirect estimates for all cohorts, but only in the case of those middle aged (30-59) is the list/direct difference (11pp) statistically significant. However, for questions regarding defector-

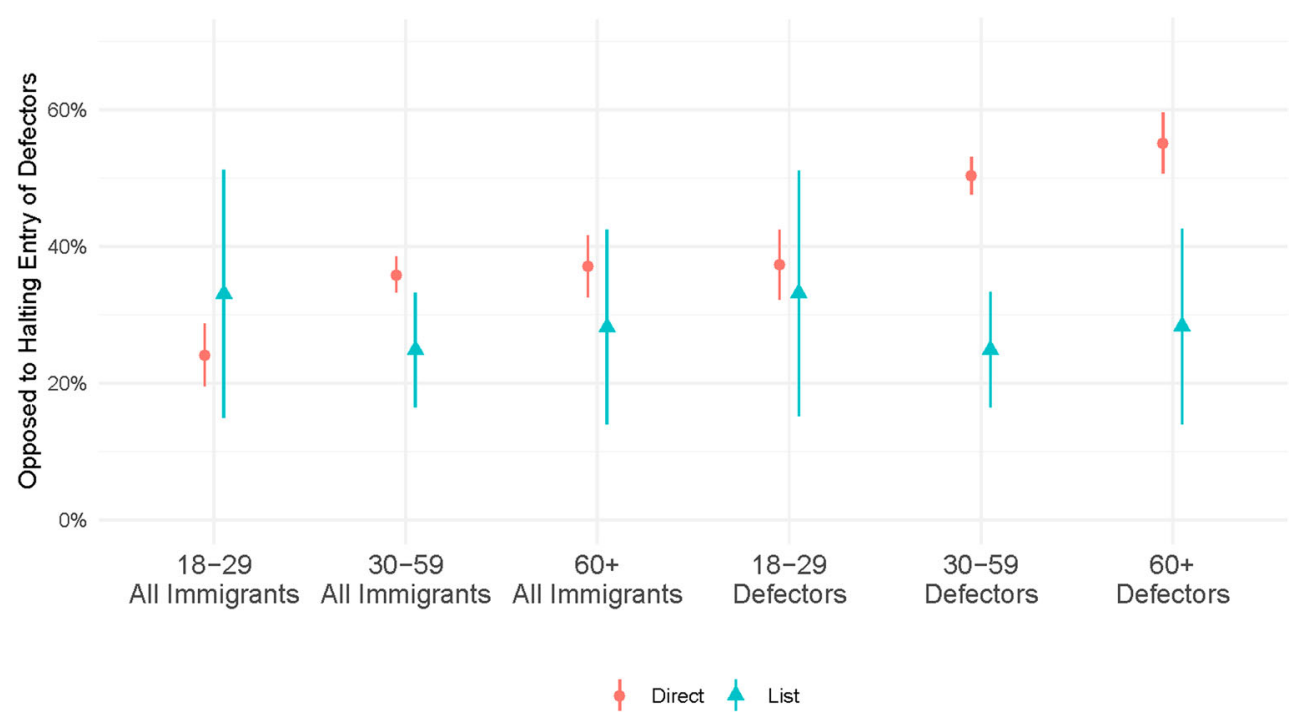

Figure 4. South Korean Attitudes Towards Defectors by Age Cohort, Immigrant, and Question Type. Error bars represent $95 \%$ confidence intervals. 
migrant entry, we find clear evidence of social desirability effects. Those 30 and older are clearly motivated to conceal their true preferences towards co-ethnics from North Korea. The difference for both the middle age and older cohort is $24 \mathrm{pp}$ and $27 \mathrm{pp}$, respectively. For the 18-29 age cohort, there is little difference between the direct and indirect point estimates (4pp). The main takeaway here is that young South Koreans do not falsify their preferences regarding co-ethnics (from North Korea) or general immigrants.

Do effects differ by educational cohorts? In Figure 5, we look at differences between those with at least some college education to those without. We find evidence that college-educated respondents overstate their support for immigration; the 11pp difference is statistically significant. Those without any college education, however, do not conceal true preferences when asked directly. For defector-migrants, both groups overstate their support when asked directly. Interestingly, those with some college overstate their support more than those without by $6 \mathrm{pp}$.

Lastly, we determine whether there are any differences by gender, with a focus on males. In Figure 6, we see notable differences in treatment effects by gender, with men overstating their support for immigration when asked directly by 17pp (females do not). Males also hugely overstate their support for defector-migrants (a 34pp direct-list difference) compared to females (only 11pp). The gendered differences are notable, but not surprising. The literature cited above indicates that opinions regarding national identity and nationhood are gendered, and in a way that gives rise to strong male social expectations. We tie the findings from this section on heterogeneous treatment effects with the overall findings from the research in the conclusion and discussion section, to which we now turn.

\section{Conclusion and discussion}

Our research findings indicate that social desirability effects with respect to immigration attitudes manifest in Korea. This occurs with specific, locally conditioned characteristics, some of which contrast with conventional understandings of Korean society and culture.

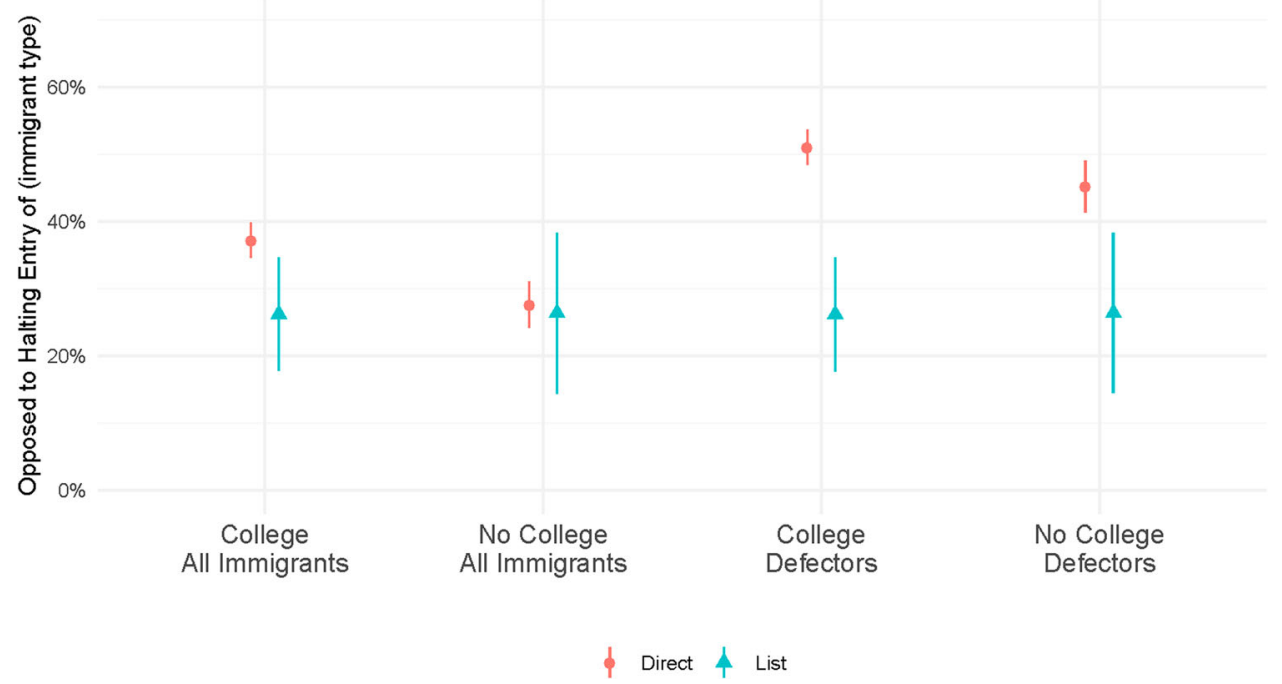

Figure 5. South Korean Attitudes Towards Defectors by Education, Immigrant, and Question Type. Error bars represent $95 \%$ confidence intervals. 


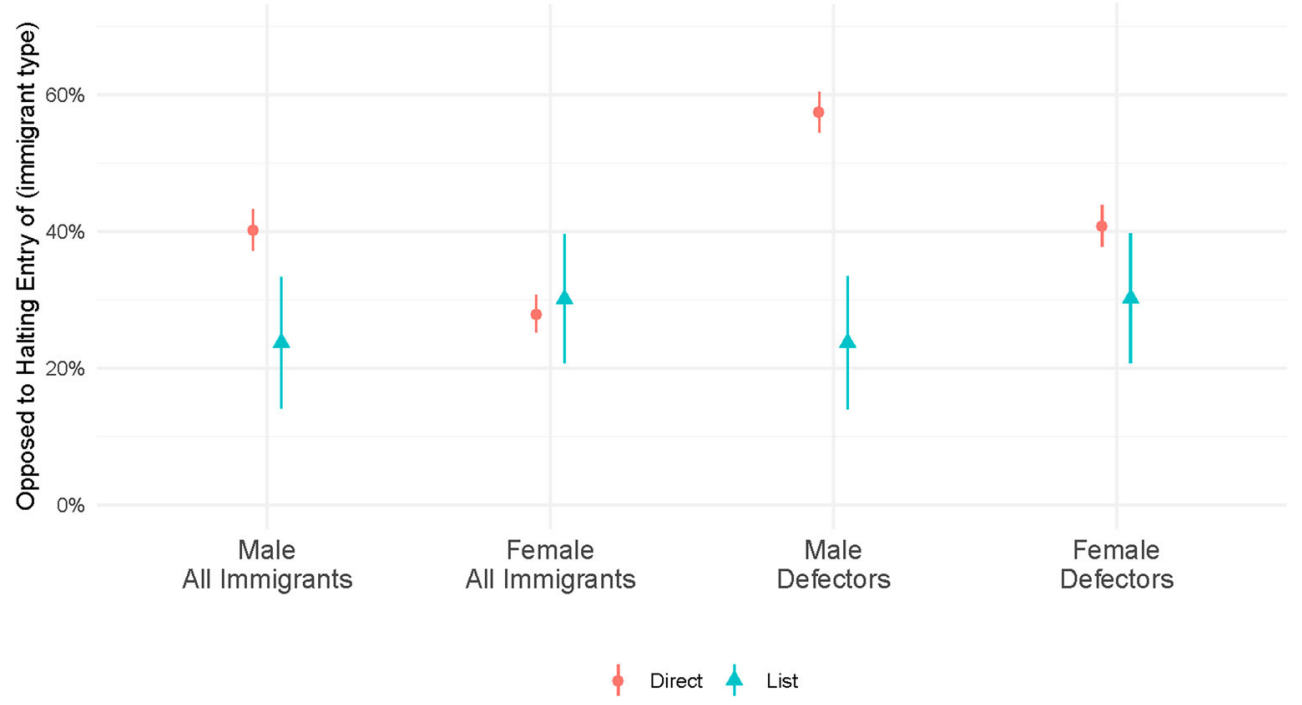

Figure 6. South Korean Attitudes Towards Defectors by Gender, Immigrant, and Question Type. Error bars represent $95 \%$ confidence intervals.

First, we find no evidence of social desirability bias in direct estimates of support for general immigration. South Koreans see little reason to falsify their preferences on this topic. Conversely, we find substantial social desirability bias in the estimates based on direct questions about barring North Korean defector-migrant entry to South Korea. When asked directly, approximately half of respondents said they oppose the extreme policy measure, but when asked indirectly, results fell into line with attitudes toward doing the same for both the all immigrants and Chinese Korean groups.

In other words, contrary to regularly articulated preferences in support of North Korean arrivals, defector-migrants are viewed no differently than other immigrants. The results presented indicate that support for North Korean migration is no lower or higher than that of migration in general, or indeed for Chinese Korean migration. These attitudes are arguably a consequence of multicultural notions of citizenship that de-emphasize ethnicity. Co-ethnic solidarity appears to have given way to relative indifference toward the ethnic identity of migrants.

Interestingly, ambivalent attitudes are masked by social desirability bias to differing extents among social groups, with additional and notable effects being discovered. First, we show that those aged 18-29 are the only group for whom there is not definitive evidence of social desirability in stated preferences toward defector-migrants immigrating to South Korea. This is an interesting and important finding that provides corroborating support for research indicating that there is an active de-linking of ethnicity from national identity for younger South Koreans and, therefore, less support for pan-Korean conceptions of identity and belonging (cf. Campbell 2016; Denney 2019). The 18-29 age cohort apparently feel little or no pressure to meet the social expectation to express ethnic solidarity with North Korean co-ethnics, unlike their elders.

We also find evidence that college-educated respondents overstate their support for general immigration when asked directly, which is in keeping with findings from the United States (Janus 2010; An 2015). Additionally, better-educated South Koreans are, 
relative to their less-educated peers, also greatly affected by social expectations to express solidarity with co-ethnics from North Korea. The university experience in South Korea would appear to further entrench social expectations about how one ought to think about co-ethnics from North Korea.

Finally, we also show evidence of a unique gender effect, where males - and only males - overstate their support of general immigration if asked directly. There is also a far greater difference for males than females between the direct and indirect estimates regarding defector-migrants, indicating that men exhibit greater social desirability bias in their answers to the direct question. As far as support for defector-migrants is concerned, this phenomenon may have something to do with expectations about co-ethnic solidarity instilled during mandatory military service, a nationalistic experience that applies only to males. For general immigration, the answer is not obvious. There is a case to be made, and supported here, that South Korea is a strictly gendered society, more so than others (cf. Moon 2005). Much more so than females, South Korean males show evidence of strongly instilled social desirability biases, even though their true preferences, as revealed through the list, are effectively similar to females. There is clearly more work to be done here.

That the effects we found for North Korean migrants were not present for Chinese Koreans shows that not all co-ethnic migration is subject to social desirability bias, and that at a minimum, the contours of Korean ethnic nationalism are open to debate. The reasons for the lack of support shown to Chinese Koreans deserve further research, but we can speculate as to why respondents may feel less obliged by social pressures to hide indifference or skepticism for migration of co-ethnics from China. Chinese Koreans are citizens of a large, nearby country with which South Korea has significant areas of political and economic difference. Until the establishment of diplomatic relations between Seoul and Beijing in 1992, the Chinese Korean community had far deeper links to North Korea than the South. Even today, Seoul makes little effort to foster a social obligation to express solidarity with this group; it does not finance programs aimed at fostering national solidarity with overseas Koreans to anything approaching the same extent as it does with so-called 'unification education' (Green and Epstein 2013). The result appears to be that in South Korean eyes, Chinese Koreans remain Chinese first, and Korean second.

What, then, do the research findings mean broadly? We propose two main takeaways. First, there is a disconnect between elite and public opinion regarding the long-standing concept of a pan-Korean nation. Evidence presented in this paper demonstrates a popular skepticism about the existing elite-driven consensus surrounding the goal of bringing about Korean unification and pressure, manifested in the constitution, to accept and support North Korean defector-migrant resettlement. South Koreans are not as sanguine about the resettlement of North Korean co-ethnics as is commonly believed. Our results indicate that certain public policy measures (e.g. unification education) may no longer have - if those measures ever had - the desired impact of cultivating a more supportive view of newcomers from North Korea. Creating taboos around the issue (i.e. 'true' Koreans support co-ethnics from the North) has served to occlude true preferences, but perhaps not to change them. In fact, the findings presented in this research suggest that South Koreans may see North Korean defector-migrants as little different to other immigrant groups in the costs and benefits they create for South Korean society.

Second, our results indicate that the kinds of existing observational (survey) techniques that are widely used in South Korea are problematic, at best, for gathering data about 
sensitive issues relating to North Korea. That we find evidence of social desirability bias in answers to sensitive questions is not a new finding, per se, yet we see no evidence that public opinion analysis, especially as it relates to North Korea, takes this into account. If South Korean respondents are more likely to falsify their responses regarding opposition to ending North Korean defector-migrant immigration, they may also be predisposed to do so on other sensitive questions. While the research presented here focuses on co-ethnic migration only, it stands to reason that social desirability would affect survey responses to related questions, including those about unification and North Korea policy. The research findings should therefore be noteworthy for those interested in conducting research on social integration of defector-migrants (or other co-ethnics) into South Korea and the potential future unification of the two Koreas.

Future South Korean government policy seems set to encourage immigration as a policy response to the country's low birth-rate and labor-market demands. As the immigrant population continues to grow, it will be intriguing to observe how this impacts attitudes and social expectations regarding other newcomers to the country. Researchers and policymakers alike may wish to be more mindful of social desirability bias than is currently the case, and take the appropriate steps to take its effects into consideration when studying South Korean attitudes towards the immigration of co-ethnics and non-Koreans alike.

\section{Notes}

1. A term meaning those North Koreans who escape from their country and resettle in South Korea. We use the term in this paper without any intent to transmit a political message of any kind; only, 'defector-migrant' conveys the wide range of possible motivations behind acts of abandoning North Korea for a different life in the South; it achieves this more accurately, we believe, than either 'defector' or 'migrant' (though we occasionally use 'migrant' for readability), the neologism 'saetomin', meaning 'new settler', or 'Bukhan ital jumin', meaning 'resident [of South Korea] who left North Korea'.

2. Authors' interview with North Korean defector-migrant, Seoul, ROK, June 2016.

3. Sample size limitations preclude us from exploring treatment effects for the Chinese Korean group.

4. Korea Immigration Service, http://www.index.go.kr/potal/main/EachDtlPageDetail.do?idx_ $\mathrm{cd}=2756$ (last accessed August 4, 2019).

5. Immigration data is based on 2017 numbers provided by the Ministry of the Interior and Safety and 2018 data from the Ministry of Unification on defector-migrants.

6. Growth rates will nonetheless decline, but on current trends, only through the introduction of an immigrant population equating to around one-third of the entire population will economic stagnation be avoided post-2050.

7. World Bank data. See: https://data.worldbank.org/indicator/NY.GDP.MKTP.KD.ZG?end= 2018\&locations $=\mathrm{KR} \&$ start $=1961$ \&view $=$ chart

8. This would equate to a more than four-fold increase in the number of foreign workers and would result in non-Koreans accounting for approximately $10 \%$ of the population.

9. This can be viewed as a function of co-ethnic capital (cf. Kim 2016).

10. It is true that there are some differences between the dialects of Korean spoken in North and South, but the two are still recognizably variations of Korean and mutually understood with only modest effort.

11. It is important to note that unlike other co-ethnic migrants and other migrant groups, this group is also accepted unconditionally by the South Korean state, becoming citizens by right under the constitution. This normative component cannot be omitted from consideration. 
12. Although those Chinese Koreans who migrate to South Korea for work, study, or marriage usually do speak Korean - a dialect inflected by a history of migration from nearby Hamgyeong Province - they do not share the same constitutionally mandated right to Republic of Korea citizenship, and many report being treated more like migrant labor than part of the national fabric. Their treatment is primarily a reflection of Korean economic needs, but China's role is also salient. See Choi (2016, 256-258) and Seol and Skrentny (2009).

13. Similar techniques include endorsement experiments (Bullock, Imai, and Shapiro 2011) and the randomized response technique (Warner 1965; Blair, Imai, and Zhou 2015). The research presented here uses only the list experiment.

14. Exact question wording and an overview of the descriptive statistics for the direct questions are provided in Appendices A and B of the Supplementary Information (SI) document for this article.

15. Using the most recent census (2015), quotas based on age, gender, and geography were set for the opt-in panels. All respondents are native-born Koreans and currently reside in the country. See Appendix A in the Supplementary Information for more information.

16. The list-direct comparisons were subjected to a means tests of differences, an integrated function part of the 'list' package in $\mathrm{R}$ we used to conduct our analysis. Fore more, see: https:// cran.r-project.org/web/packages/list/list.pdf

17. See Appendix A for specific question wording and variable construction.

18. To determine whether we reject the null hypothesis of no design effect, we use the proposed statistical tests set forth by Blair and Imai (2012, 62-65), finding no evidence of design effects. Further, examining the distribution of responses for the list experiments across the control and treatment (see Appendix B), we also conclude that there are no ceiling or floor effects.

19. Results from balance testing for the combined samples is provided in Appendix B.

20. South Koreans who go into higher education (which varies at around 70 percent of those eligible) spend four years in university, and few combine education and employment (OECD 2019). Males must additionally spend a maximum of one year and nine months in the military. Graduates therefore generally enter the workforce later than in other countries, at or around mid- to late-20s. The early 30 s are thus initial, prime working years of young South Koreans, and this is evident from the difference in labor force participation rates between South Koreans in their 20 s, only $60 \%$ of whom were engaged in economic activity in March 2020, whereas rates for people in their 30s-50s were all nearly $80 \%$, with a steep drop post-60 to $43 \%$ (Statistics Korea 2020).

\section{Acknowledgements}

The authors would like to acknowledge the assistance of several people. At the University of Toronto, Michael Donnelly, Lior Sheffer, Joseph Wong, and Zain Asaf offered helpful feedback and advice in the research design stage. Aram Hur (University of Missouri) and Stephen Epstein (Victoria University of Wellington) provided valuable comments on an earlier draft. The entire project team at Delvinia in Toronto delivered crucial programming assistance and survey management, specifically Nicole Caldaraelli, Grace Choe, and Roy Gonsalves. Lastly, we are grateful for the constructive criticism and comments from two anonymous reviewers.

\section{Disclosure statement}

No potential conflict of interest was reported by the author(s).

\section{Funding}

This work was supported by UniKorea Foundation 2018-19 Research Grant. https://www. tongilnanum.com/unishare/program/index.jsp\#programIntroduce. 


\section{Data availability statement}

Replication material can be accessed at GitHub: https://github.com/scdenney/Korea_list_ experiments.

\section{ORCID}

Steven Denney (iD http://orcid.org/0000-0002-6542-1055

\section{References}

An, Brian P. 2015. "The Role of Social Desirability Bias and Racial/Ethnic Composition on the Relation Between Education and Attitude Toward Immigration Restrictionism." The Social Science Journal 52: 459-467. doi:10.1016/j.soscij.2014.09.005.

Blair, Graeme, and Kosuke Imai. 2012. "Statistical Analysis of List Experiments." Political Analysis 20: 47-77. doi:10.1093/pan/mpr048.

Blair, Graeme, Kosuke Imai, and Yang-Yang Zhou. 2015. "Design and Analysis of the Randomized Response Technique." Journal of the American Statistical Association 110 (511): 1304-1319. doi:10.1080/01621459.2015.1050028.

Boyon, Nicolas. 2018. The Inclusiveness of Nationalities: A Global Advisor Survey.” Report, Ipsos Public Affairs. Accessed on October 11, 2019. https://www.ipsos.com/sites/default/files/ct/news/ documents/2018-06/the-inclusiveness-of-nationalities-ipsos-global-advisor.pdf.

Bullock, Will, Kosuke Imai, and Jacob N. Shapiro. 2011. "Statistical Analysis of Endorsement Experiments: Measuring Support for Militant Groups in Pakistan.” Political Analysis 19 (4): 363-384. doi:10.1093/pan/mpr031.

Burns, Peter, and James G. Gimpel. 2000. "Economic Insecurity, Prejudicial Stereotypes, and Public Opinion on Immigration Policy.” Political Science Quarterly 115: 201-225. doi:10.2307/2657900.

Campbell, Emma. 2016. South Korea's New Nationalism: The End of 'One Korea?'. Boulder, CO: Lynne Rienner.

Chang, Andy G., and T. Y. Wang. 2005. "Taiwanese or Chinese? Independence or Unification? An Analysis of Generational Differences in Taiwan." Journal of Asian and African Studies 40 (1-2): 29-49.

Cho, Gyeong-eop, and Dong-gwan Kang. 2015. The Need to expand immigration and it's economic effects [이민 확대의 필요성과 경제적 효과]. KERI Policy Research 2014-21 [정책연구 201421].

Choe, Sang-hun. 2018. "Just 2 of More Than 480 Yemenis Receive Refugee Status in South Korea." New York Times, December 14.

Choi, Woogill. 2016. "The Transformation of the Korean Chinese Community: The Case of the Age of Migration in China." Journal of Contemporary Korean Studies 3 (1-2): 245-264.

Creighton, M. J., A. Jamal, and N. C. Malancu. 2015. "Has Opposition to Immigration Increased in the United States After the Economic Crisis?" An Experimental Approach. International Migration Review 49 (3): 727-756. doi:10.1111/imre.12091.

Denney, Steven. 2019. "Does Democracy Matter? Political Change and National Identification in South Korea and Beyond." PhD diss., University of Toronto.

Donnelly, Michael. 2017. Canadian Exceptionalism: Are We Good or Are We Lucky? McGill Institute for the Study of Canada (MISC), February.

Fussell, Elizabeth. 2014. "Warmth of the Welcome: Attitudes Toward Immigrants and Immigration Policy in the United States." Annual Review of Sociology 40: 479-498.

Gaasholt, Oystein, and Lise Togeby. 1995. "Interethnic Tolerance, Orientation: Evidence From Denmark." Political Behavior 17: 265-285.

Gilens, Martin, Paul M. Sniderman, and James Kuklinski. 1998. "Affirmative Action and the Politics of Realignment.” British Journal of Political Science 28: 159-118. 
Gonzalez-Octanos, Ezequiel, Chad Kiewiet de Jonge, Carlos Melendez, Javier Osorio, and David W. Nickerson. 2012. "Vote Buying and Social Desirability Bias: Experimental Evidence From Nicaragua." American Journal of Political Science 56 (1): 202-217. doi:10.1111/j.1540-5907. 2011.00540.x.

Green, Christopher K., and Stephen J. Epstein. 2013, October 14. "Now on My Way to Meet Who? South Korean Television, North Korean Refugees, and the Dilemmas of Representation." The Asia-Pacific Journal 11 (41.2).

Ha, Shang E., Soo Jin Cho, and Jeong-Han Kang. 2016. "Group Cues and Public Opposition to Migration: Evidence From a Survey Experiment in South Korea." Journal of Ethnic and Migration Studies 42 (1): 136-149. doi:10.1080/1369183X.2015.1080608.

Hainmueller, Jens, and Michael J. Hiscox. 2007. "Educated Preferences: Explaining Attitudes Toward Immigration in Europe.” International Organization 61 (2): 399-442.

Holbrook, Allison L., and Jon A. Krosnick. 2010. "Measuring Voter Turnout by Using the Randomized Response Technique: Evidence Calling Into Question the Method's Validity." Public Opinion Quarterly 74 (2): 328-343. doi:10.1093/poq/nfq012.

Hough, Jennifer. 2017. "North Koreans in South Korea: Humanitarian Subjects and Neoliberal Governance." PhD thesis, University of Oxford.

Imai, Kosuke. 2011. "Multivariate Regression Analysis for the Item Count Technique." Journal of the American Statistical Association 106 (494): 407-416. doi:10.1198/jasa.2011.ap10415.

IOM. 2017. "South Korea Welcomes 30 Myanmar Refugees from Thailand.” July 28, 2017. Accessed 16 August 2019. https://www.iom.int/news/south-korea-welcomes-30-myanmar-refugeesthailand.

Janus, A. L. 2010. "The Influence of Social Desirability Pressures on Expressed Immigration Attitudes*." Social Science Quarterly 91: 928-946. doi:10.1111/j.1540-6237.2010.00742.x.

Jeong, Dong-jun, Seon Kim, Hee-jeong Kim, Yong-u Na, In-cheol Mun, Yeong-hun Song, Gyu-bin Choe, Gyeong-hun Lim, and Jeong-uk Lee. 2018. Unification Perception Survey 2018 [2018 통일의식조사]. Seoul: Seoul National University Institute for Peace and Unification Studies.

Kane, J. G., Stephen C. Craig, and Kenneth D. Wald. 2004. "Religion and Presidential Politics in Florida: A List Experiment*." Social Science Quarterly 85: 281-293. doi:10.1111/j.0038-4941. 2004.08502004.x.

Kang, Dong-gwan, Sang-ho Nam, Seo-ri Choe, Chang-won Lee, Eung-sun Im, Yeon-su Kim, and Ga-yeon Yun. 2015. Scale of Immigration required to maintain the state's growth dynamism and priorities (Basic Research regarding potential growth rates 1) [국가의 성장동력 유지 등을 위한 이민자 도입규모와 우선순위 연구(잠재성장률에 따른 기초연구1)]. Ministry of Justice Research Report.

Kim, Nadia Y. 2006. ““Patriarchy is So Third World”: Korean Immigrant Women and 'Migrating' White Western Masculinity." Social Problems 53 (4): 519-536.

Kim, Nora Hui-Jung. 2015. "The Retreat of Multiculturalism? Explaining the South Korean Exception.” American Behavioral Scientist 59 (6): 727-746. doi:10.1177/0002764214566497.

Kim, Nora Hui-Jung. 2016. "Naturalizing Korean Ethnicity and Making 'Ethnic' Difference: a Comparison of North Korean Settlement and Foreign Bride Incorporation Policies in South Korea." Asian Ethnicity 17 (2): 185-198. doi:10.1080/14631369.2016.1151234.

Kim, I-seon, Yun-jeong Choe, Ji-so Yun, Jae-gyeong Lee, Hee-yeong Mun, Myeong-jin Lee, and Gye-min Yang. 2018. 2018 Citizens Multiculturalism Acceptance Survey [2018년 국민 다문화수용성 조사]. Ministry of Gender Equality and Family Policy Report.

Kim, Byung-yeon, and Jungmin Lee. 2018. Cognitive Ability and Economic Outcomes of North Korean Refugees." [북한이탈주민의 인지적 능력과 경제적 성과].” Economic Research 66 (1): $5-31$.

Kim, Hyun-Soo, Yong-Soon Lee, and Min-Kyoo Kim. 2013. "Study on Enhancing Competency for Employability of North Korean Refugees.” Report, Korea Research Institute for Vocational Education \& Training.

Kim, Yoon-Sun, and In-Jin Yoon. 2015. "Multiculturalism Is Good, But We Are Not Multicultural: North Korean Defector Students' Perceptions of Multiculturalism.” The Korea Educational Review 21 (2): 325-350. 
Kramon, Eric, and Keith Weghorst. 2019. “(Mis)Measuring Sensitive Attitudes with the List Experiment.” Public Opinion Quarterly 83 (S1): 236-263. doi:10.1093/poq/nfz009.

Krumpal, Ivar. 2013. "Determinants of Social Desirability Bias in Sensitive Surveys: a Literature Review.” Quality \& Quantity 47 (4): 2025-2047. doi:10.1007/s11135-011-9640-9.

Krysan, Maria. 1998. "Privacy and the Expression of White Racial Attitudes: A Comparison Across Three Contexts." Public Opinion Quarterly 62: 506-544. doi:10.1086/297859.

Kuklinski, James, Paul M. Sniderman, Kathleen Knight, Thomas Piazza, Philip E. Tetlock, Gordon R. Lawrence, and Barbara Mellers. 1997. "Racial Prejudice and Attitudes Toward Affirmative Action." American Journal of Political Science 41 (2): 402-419. doi:10.2307/2111770.

Kunovich, Robert M. 2009. "The Sources and Consequences of National Identification." American Sociological Review 74 (4): 573-593.

Kwon, Insook. 2001. "A Feminist Exploration of Military Conscription: The Gendering of the Connections Between Nationalism, Militarism and Citizenship in South Korea." International Feminist Journal of Politics 3 (1): 26-54.

LaBrie, Joseph W., and Mitchell Earleywine. 2000. "Sexual Risk Behaviors and Alcohol: Higher Base Rates Revealed Using the Unmatched-Count Technique.” Journal of Sex Research 37 (4): 321 326. doi:10.1080/00224490009552054.

Lee, Sohoon, and Yi-Chun Chien. 2017. "The Making of 'Skilled' Overseas Koreans: Transformation of Visa Policies for Co-Ethnic Migrants in South Korea." Journal of Ethnic and Migration Studies 43 (13): 2193-2210.

Lee, Sang-sin, Geum-sun Lee, Seok-hun Hong, Gwang-il Yun, Bon-sang Gu, and Joshua D. Kertzer. 2018. KINU Unification Perception Survey 2018: Unification Perception in the era of North-South Peace [KINU 통일의식조사 2018: 남북평화 시대의 통일의식]. KINU Research Volume 1807.

Lim, Timothy. 2017. “The Road to Multiculturalism in South Korea." Georgetown Journal of International Affairs. October 10. Accessed August 2, 2019. https://www. georgetownjournalofinternationalaffairs.org/online-edition/2017/10/10/the-road-tomulticulturalism-in-south-korea.

Lim, Timothy, and Dong-Hoon Seol. 2018. "Explaining South Korea's Diaspora Engagement Policies.” Journal of Asian Sociology 47 (4): 633-662. doi:10.21588/dns/2018.47.4.006.

Martinez, Michael D., and Stephen C. Craig. 2010. "Race and 2008 Presidential Politics in Florida: A List Experiment." The Forum 8 (2.4). doi:10.2202/1540-8884.1316.

Mayda, Anna Maria. 2006. "Who Is Against Immigration? A Cross-Country Investigation of Individual Attitudes Towards Immigrants.” The Review of Economics and Statistics 88 (3): 510-530.

Moon, Seungsook. 2005. Militarized Modernity and Gendered Citizenship in South Korea. Durham: Duke University Press.

Norris, Pippa, and Ronald Inglehart. 2019. Cultural Backlash: Trump, Brexit, and Authoritarian Populism. Cambridge: Cambridge University Press.

OECD. 2019. "Investing in Youth: Korea." Report. Accessed April 26, 2019. https://www.oecdilibrary.org/sites/63797b4a-en/index.html?itemId=/content/component/63797b4a-en.

Oh, David C., and Chuyun Oh. 2016. "Until You Are Able': South Korean Multiculturalism and Hierarchy in My Little Hero." Communication, Culture and Critique 9 (2): 250-265.

Ponce, Aaron. 2017. "Gender and Anti-Immigrant Attitudes in Europe." Socius 3: 1-17.

Poushter, Jacob, Janell Feteerfolf, and Christine Tamir. 2019. "A Changing World: Global Views on Diversity, Gender Equality, Family Life and the Importance of Religion.” Report, Pew Center Research. Accessed October 11, 2019. https://www.pewresearch.org/global/wp-content/ uploads/sites/2/2019/04/Pew-Research-Center_Global-Views-of-Cultural-Change_2019-04-22. pdf.

Rayburn, Nadine Recker, Mitchell Earleywine, and Gerald C. Davison. 2003. "An Investigation of Base Rates of Anti-Gay Hate Crimes Using the Unmatched-Count Technique.” Journal of Aggression, Maltreatment \& Trauma 6 (2): 137-152. doi:10.1300/J146v06n02_07. 
Seol, Dong Hoon, and John D. Skrentny. 2009. "Ethnic Return Migration and Hierarchical Nationhood: Korean Chinese Foreign Workers in South Korea." Ethnicities 9 (2): 147-174. doi:10.1177/1468796808099901.

Sorensen, Marianne, and Harvey Krahn. 1996. "Attitudes Toward Immigrants: A Test of Two Theories.” Alberta Journal of Educational Research 42: 3-18.

Statistics Korea. 2020. Economic Activity Population Survey [경제활동인구조사]. http://kosis.kr/ statHtml/statHtml.do?orgId=101\&tblId=DT_1DA7012S.

Walsh, Jeffrey A., and Jeremy Braithwaite. 2008. "Self-Reported Alcohol Consumption and Sexual Behavior in Males and Females: Using the Unmatched-Count Technique to Examine Reporting Practices of Socially Sensitive Subjects in a Sample of University Students." Journal of Alcohol and Drug Education 52 (2): 49-74.

Warner, Stanley L. 1965. "Randomized Response: A Survey Technique for Eliminating Evasive Answer Bias." Journal of the American Statistical Association 60 (309): 63-69. doi:10.1080/ 01621459.1965.10480775.

Yoon, In-Jin. 2016. "Changes in Koreans' Perceptions of Multiculturalism and Multicultural Minorities: From Paternalism to Indifference?” [한국인의 다문화와 다문화 소수자에 대한 인식 변화: 온정주의에서 냉담주의로?.] In South Korean Identity: Change and Continuity, 2005 2015 [한국인의 정체성: 변화와 연속, 2005 2015], edited by Nae-young Lee and InJin Yoon, 71-99. Seoul: East Asia Institute.

Yu, Shi-Eun, Byung-Yeon Kim, Woo-Taek Jeon, and Seung-Ho Jung. 2012. "Determinants of Labor Market Participation and Wages of North Korean Female Refugees in South Korea." Asian Economic Policy Review 7 (1): 113-129. doi:10.1111/j.1748-3131.2012.01224.x. 